\title{
ORIGINAL ARTICLE \\ Severity of obesity and management of hypertension, hypercholesterolaemia and smoking in primary care: population-based cohort study
}

\author{
HP Booth, AT Prevost and MC Gulliford
}

\begin{abstract}
Obesity and obesity-associated cardiovascular risk are increasing worldwide. This study aimed to determine how different levels of obesity are associated with the management of smoking, hypertension and hypercholesterolaemia in primary care. We conducted a cohort study of adults aged 30-100 years in England, sampled from the primary care electronic health records in the Clinical Practice Research Datalink. Prevalence, treatment and control were estimated for each risk factor by body mass index (BMI) category. Adjusted odds ratios (AOR) were estimated, allowing for age, gender, comorbidity and socioeconomic status, with normal weight as reference category. Data were analysed for 247653 patients including 153308 (62\%) with BMI recorded, of whom 46149 (30\%) were obese. Participants were classified into simple (29 257), severe (11 059) and morbid obesity (5833) categories. Smoking declined with the increasing BMl category, but smoking cessation treatment increased. Age-standardised hypertension prevalence was twice as high in morbid obesity (men 78.6\%; women 66.0\%) compared with normal weight (men 37.3\%; women 29.4\%). Hypertension treatment was more frequent (AOR 1.75, 1.59-1.92) but hypertension control less frequent (AOR 0.63, 0.59-0.69) in morbid obesity, with similar findings for severe obesity. Hypercholesterolaemia was more frequent in morbid obesity (men 48.2\%; women 36.3\%) than normal weight (men 25.0\%; women 20.0\%). Lipid lowering therapy was more frequent in morbid obesity (AOR 1.83, 1.61-2.07) as was cholesterol control (AOR 1.19, 1.06-1.34). Increasing obesity category is associated with elevated risks from hypertension and hypercholesterolaemia. Inadequate hypertension control in obesity emerges as an important target for future interventions.
\end{abstract}

Journal of Human Hypertension (2016) 30, 40-45; doi:10.1038/jhh.2015.23; published online 26 March 2015

\section{INTRODUCTION}

Obesity is a growing global health concern, with a rapid increase being observed in morbid obesity. Excess body weight is associated with an increased cardiovascular risk and earlier onset of cardiovascular morbidity. ${ }^{1}$ It is well established that obesity is associated with activation of both the sympathetic nervous system and the renin-angiotensin system contributing to the emergence of hypertension. ${ }^{2}$ Epidemiological studies have demonstrated the importance of the level and duration of obesity as risk factors for cardiovascular disease. ${ }^{3}$ Improved preventive medical care to detect, treat and control of risk factors in overweight and obese patients is therefore of particular importance. ${ }^{4}$ Smoking, high blood pressure (BP) and elevated serum cholesterol levels represent major cardiovascular risk factors ${ }^{5}$ that are routinely managed in primary care settings. Deficits in risk factor detection, treatment and control are well recognised. The 'rule of halves' has been applied to hypertension management, which suggests that half of hypertension may be detected, with half of these treated and half controlled. ${ }^{6}$ In the UK general population, hypertension detection, treatment and control have improved over time with closer to 'two-thirds' now being detected, treated or controlled. ${ }^{6}$ Some studies suggest that hypertension may be less well controlled in obese patients, ${ }^{7-9}$ but few studies have been sufficiently large to analyse patients with severe and morbid obesity as separate groups. Management of hypercholesterolaemia and smoking at different levels of obesity have been less studied. ${ }^{7}$ In the UK, a population-based system of primary care, in which patients remain registered with the same general practice for many years, enables the health care system to potentially address these important concerns. This study aimed to compare the diagnosis and treatment of smoking, hypertension and hypercholesterolaemia, and control of hypertension and hypercholesterolaemia, according to body mass index (BMI) category by using the electronic health records of a large population in primary care.

\section{METHODS}

Study design and participants

CPRD is a prospectively collected database of primary care electronic health records, from $\sim 680$ UK general practices with 5.5 million currently registered patients. ${ }^{10}$ For the present study, data were sampled from CPRD general practices in England that participate in the data linkage scheme. A random sample of patients registered in CPRD, aged 30 years or older, was drawn. This provided an initial cohort of 300006 patients. These analyses evaluated records during 2011 and we included all 247653 participants, with 122903 men and 124750 women, who contributed person-time in 2011. Ethical approval for the study was given by the CPRD Independent Scientific Advisory Committee (ISAC 09_085 \& 14_056).

\section{Outcomes and covariates}

BMI records were evaluated and BMI was also calculated from weight and height records where appropriate. Measurements from up to 3 years 
previously were analysed. ${ }^{11}$ Patients were classified by BMI using the categories: underweight, $\mathrm{BMI}<18.5 \mathrm{~kg} \mathrm{~m}^{-2}$; normal weight, $18.5-24.9$ $\mathrm{kg} \mathrm{m}^{-2}$; overweight, $25.0-29.9 \mathrm{~kg} \mathrm{~m}^{-2}$; obese, $30.0-34.9 \mathrm{~kg} \mathrm{~m}^{-2}$; severe obesity, $35.0-39.9 \mathrm{~kg} \mathrm{~m}^{-2}$; and morbid obesity, $\geqslant 40 \mathrm{~kg} \mathrm{~m}^{-2}$. Patients with missing BMI status were included in the analyses as a separate category.

Smoking status was ascertained by using clinical records of smoking habits (including cigarettes, pipe, cigar and unspecified smoking) together with records of advice, referrals to stop smoking services and drug prescriptions for nicotine replacement therapy, as reported in detail previously. ${ }^{12}$ Participants not recorded as smokers or ex-smokers were classed as non-smokers. ${ }^{12}$ Records of smoking cessation advice, referrals or prescriptions for nicotine replacement therapy were used to indicate treatment for smoking cessation. 'Control' of smoking was not evaluated as clinical records of quitting and relapse may be incomplete.

Hypertension was defined as a BP reading of $\geqslant 140 / 90 \mathrm{~mm} \mathrm{Hg}$ or treatment with antihypertensive drugs. ${ }^{13}$ Antihypertensive drugs were categorised by using the ' $A B C D$ ' classification, including: $A$, angiotensinconverting enzyme inhibitors and angiotensin receptor blocking drugs; $B$, beta blockers; C, calcium channel blockers; and D, thiazide diuretics. ${ }^{13}$ Hypercholesterolaemia was defined as a total cholesterol measurement $>5 \mathrm{mmoll}^{-1}$ or treatment with lipid-lowering drugs. Treatment of each condition was assessed based on the prescription of antihypertensive drugs or lipid-lowering drugs. Successful control was defined as a BP $<140 / 90 \mathrm{~mm} \mathrm{Hg}$, or total cholesterol $\leqslant 5 \mathrm{mmoll}^{-1}$. Socioeconomic deprivation was assessed by using the Index of Multiple Deprivation rank based on patient postal code and divided into quintiles for England. ${ }^{14}$

\section{Data analysis}

Age-standardised prevalences for smoking, hypertension and hypercholesterolaemia were calculated for using the European Standard Population for reference. ${ }^{15}$ Multivariable logistic regression models were used to compare the proportion receiving treatment across BMI categories. In order to evaluate whether treatment of risk factors differed depending on the need for primary or secondary prevention, sensitivity analyses were performed by excluding patients with comorbid coronary heart disease (CHD), stroke or type 2 diabetes from analyses. Models were adjusted for age and gender, prevalent CHD, stroke, diabetes and deprivation quintile.

\section{RESULTS}

The initial cohort comprised 300006 patients. For the present analyses, we included all 247653 participants, with 122903 men and 124750 women, who contributed person-time in 2011. The mean age was 56.0 (s.d. 14.3) for men and 57.7 (s.d. 15.4) for women. There were 153308 (62\%) with BMI values recorded in the preceding three years, including 29257 (19\%) with simple obesity, 11059 (7.2\%) having severe obesity and 5833 (3.8\%) with morbid obesity. Among patients with known smoking status, $25.5 \%$ of men and $20.8 \%$ of women were current smokers.

Age-standardised prevalences for smoking, hypertension and hypercholesterolaemia by gender and BMI category are presented in Table 1. Current smoking was highest in underweight patients, at $56.4 \%$ (95\% confidence interval (Cl) 51.8-61.1) in men and $37.2 \%$ (34.5-39.8) in women. Smoking prevalence declined with increasing BMI category, reaching $21.6 \%$ (19.6-23.6) in morbidly obese men and $19.7 \%(18.3-21.0)$ in women. The prevalence of hypertension and hypercholesterolaemia rose with increasing BMI category. Hypertension was found to affect $78.6 \%$ (76.6-80.7) of morbidly obese men and $66.0 \%(64.5-67.4)$ of morbidly obese women, while hypercholesterolaemia was prevalent in $48.2 \%$ (45.9-50.4) of morbidly obese men and 36.3\% (34.9-37.7) of women. The proportion with each risk factor was generally higher in men than women in the same BMl category.

Figure 1 presents the proportion of patients with hypertension receiving antihypertensive medication by BMI category. The proportions receiving one, two, three or four classes of antihypertensive medications are also shown. As BMI category increased a higher proportion of hypertensive patients received antihypertensive drug treatment. The proportion of patients prescribed one class of drug decreased slightly in higher BMI categories, from $47 \%$ of normal weight men to $37 \%$ of morbidly obese men. However, there was only marginal increase in the proportion receiving three or four classes of antihypertensive drugs at higher levels of obesity. In women, the values were 49 and $48 \%$, respectively.

Figure 2 presents the proportion of patients with treated hypertension whose BP was controlled. As BMI category increased, the proportion with controlled hypertension did not increase in proportion to those treated, and tended to decrease in morbid obesity (Table 3). However, for hypercholesterolaemia (Figure 3) both the proportion treated and controlled increased with an increasing BMI category (Tables 2 and 3).

Table 2 presents adjusted odds ratios (AOR) for the association of BMI category with risk factor treatment. The odds of receiving treatment for each of the three risk factors increased with increasing BMI category. The effect of increasing BMI category was greatest for treatment of hypercholesterolaemia, where obesity

Table 1. Age standardised prevalence (\%) of smoking, hypertension and hypercholesterolaemia in men and women in 2011

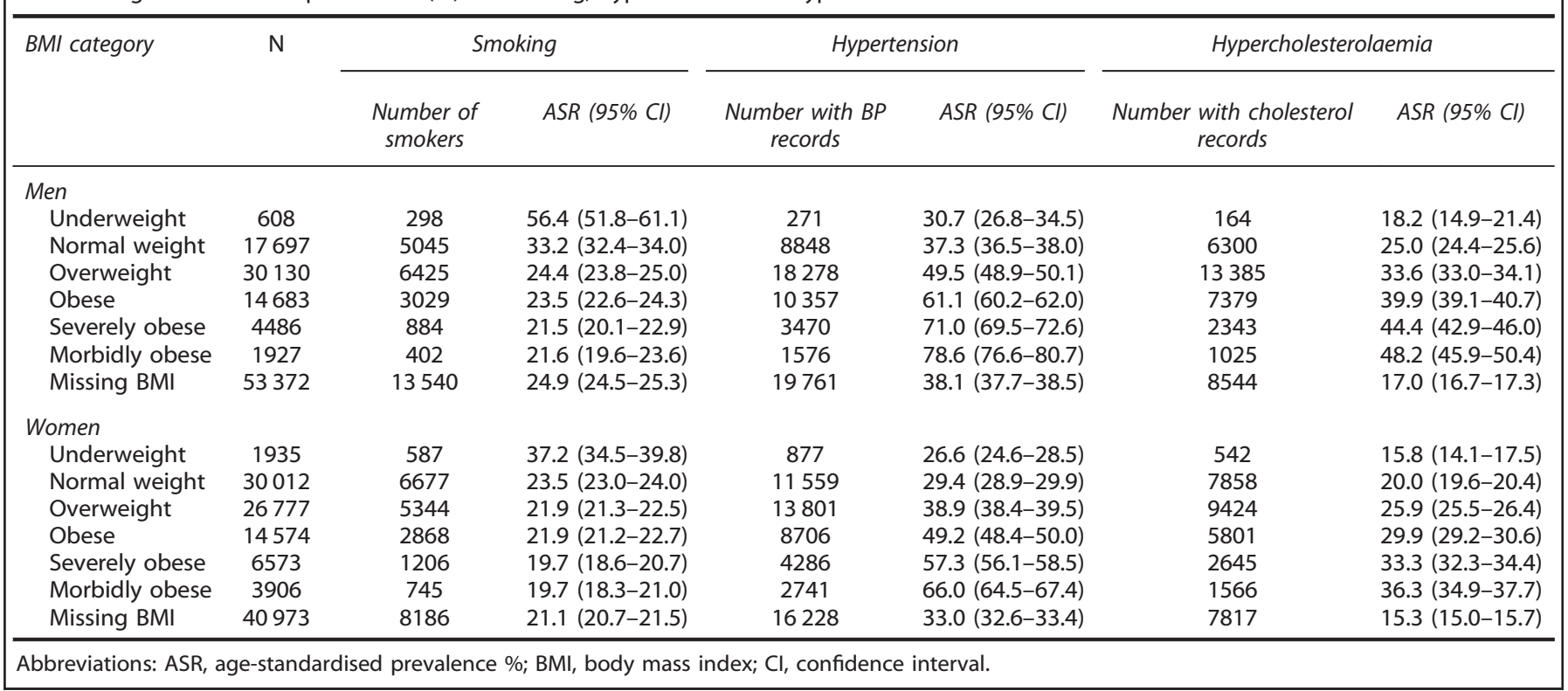



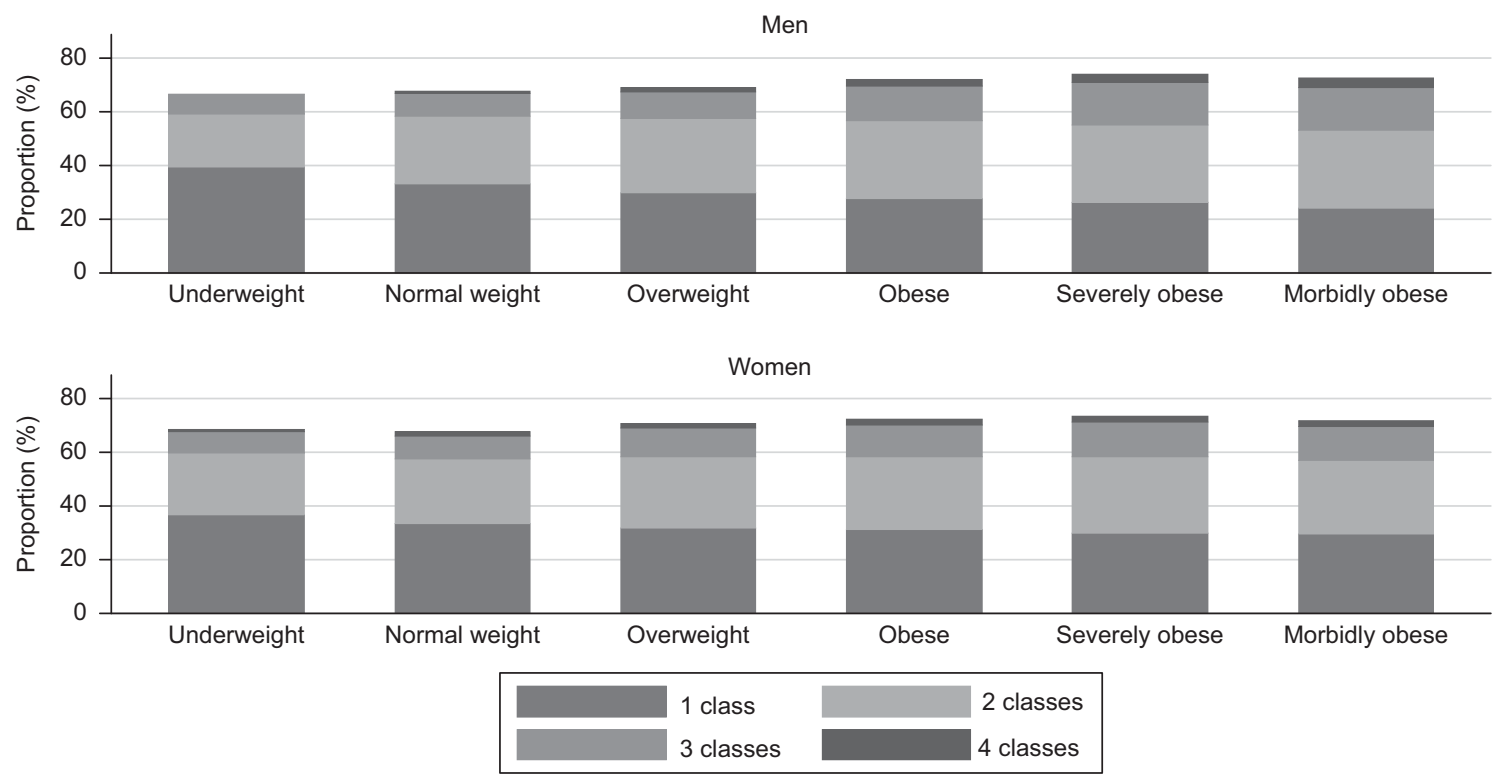

Figure 1. Use of antihypertensive drugs by BMI category. Proportion of hypertensive patients receiving different classes of antihypertensive drugs.
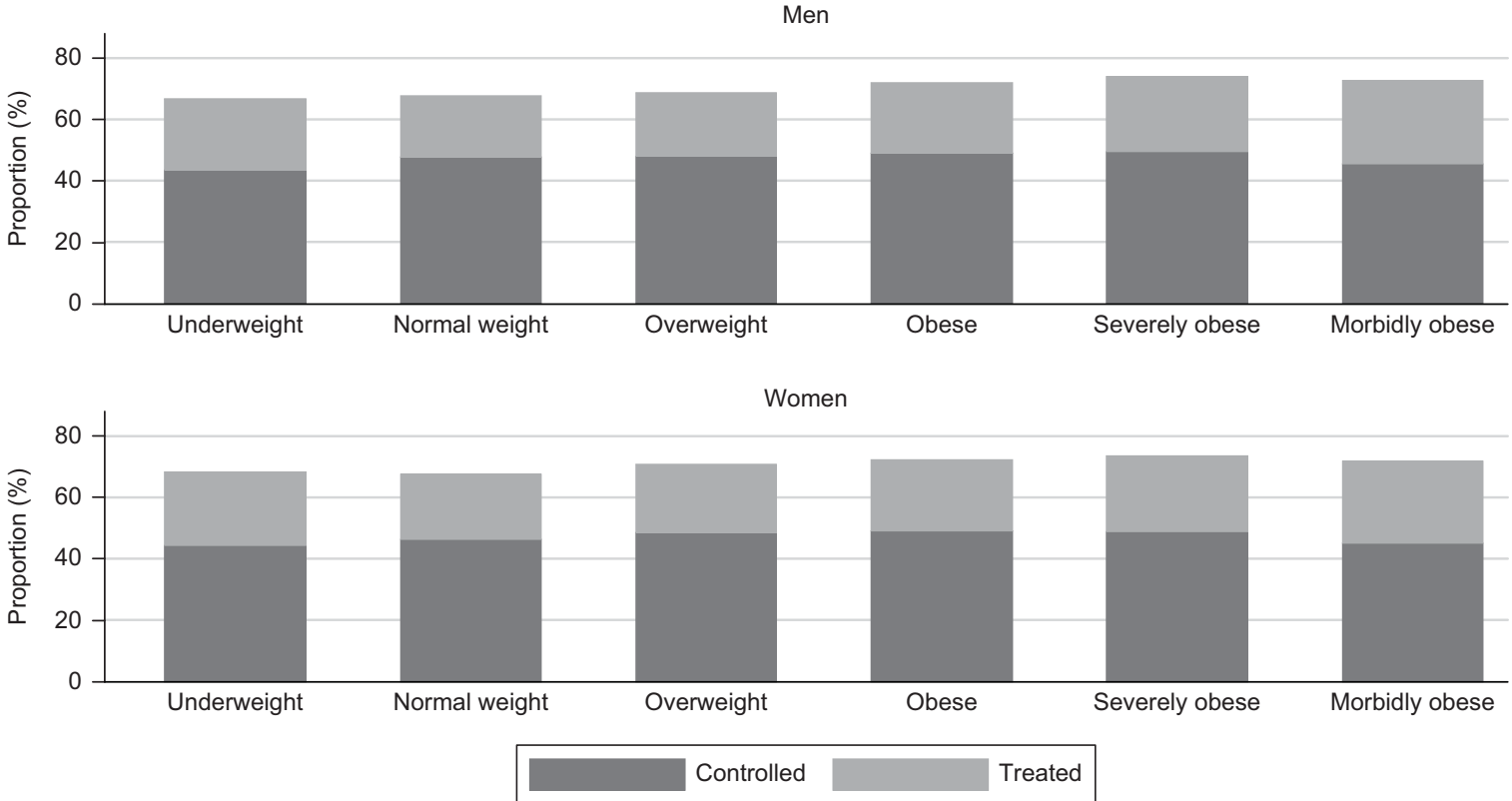

Figure 2. Treatment and control of hypertension by BMI category in 2011. Bars represent the proportion of hypertensive patients who received treatment and those with a blood pressure measurement of $<140 / 90 \mathrm{~mm} \mathrm{Hg}$.

was associated with odds of $1.59(1.48-1.72, P<0.001)$ compared with normal weight, and morbid obesity with an AOR of 1.83 (1.61-2.07, $P<0.001)$. The absolute difference in proportion treated was $10 \%$ (Table 2). For treatment of hypertension, the AOR for morbid obesity was $1.75(1.59-1.92, P<0.001)$ compared with normal weight, with an absolute difference of $4 \%$. For smoking cessation therapy the AOR was $1.32(1.11-1.58, P=0.002)$, with an absolute difference of $6 \%$. Patients with missing $\mathrm{BMI}$ status were less likely to be treated. Greater socioeconomic deprivation was associated with a greater likelihood of receiving treatment for hypertension (AOR 1.16, 95\% Cl 1.07-1.26, $P=0.001$ most deprived vs least deprived quintile) and hypercholesterolaemia (AOR 1.28, 95\% Cl 1.08-1.53, $P=0.005$ ), but not for smoking. Presence of co-morbidities was associated with greater odds of treatment for each of the risk factors. To evaluate whether obesity was associated with risk factor management in the absence of cardiovascular comorbidity, we additionally excluded data for patients with established CHD, stroke and type 2 diabetes and observed similar associations.

Increasing BMI category was associated with lower hypertension control (Table 3). Morbidly obese patients with treated hypertension had an AOR of $0.63(0.57-0.69, P<0.001)$ compared with normal weight patients and $7 \%$ fewer had their BP controlled. The odds of controlled hypercholesterolaemia were greater in morbidly obese patients compared with normal weight (AOR 1.19, $1.06-1.34, P=0.005)$, with $7 \%$ more having the cholesterol values 
Men

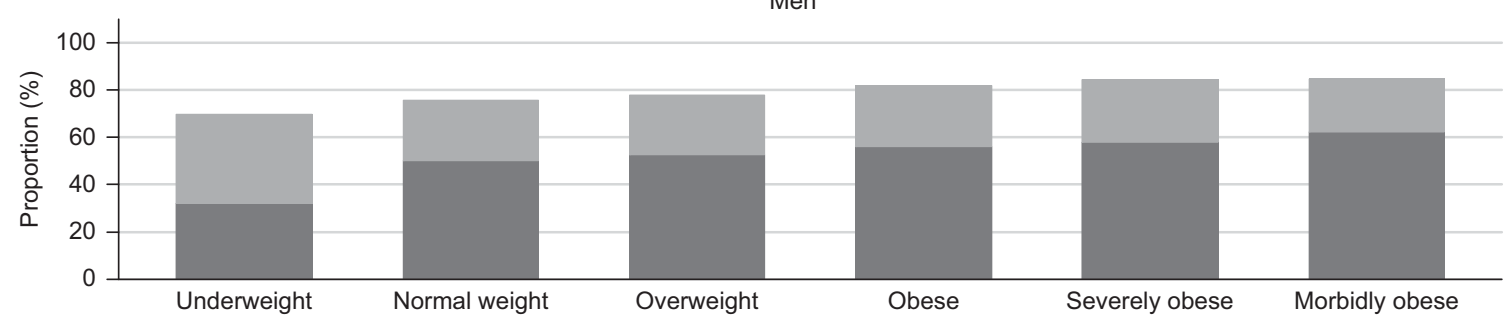

Women

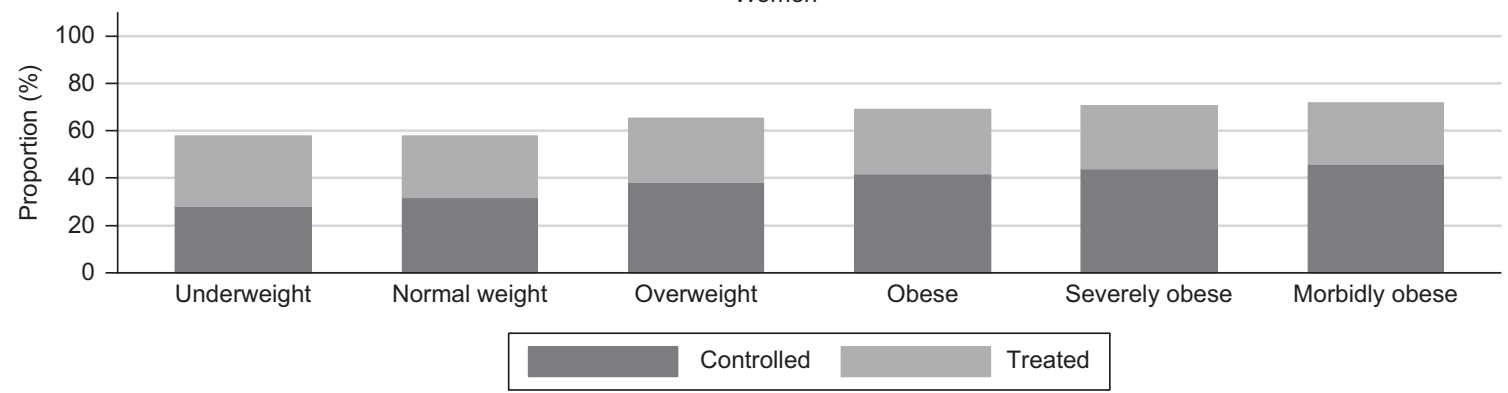

Figure 3. Treatment and control of hypercholesterolaemia by BMI category in 2011. Bars represent the proportion of patients with hypercholesterolaemia who received the treatment and those with a total cholesterol measurement of $\leqslant 5 \mathrm{mmol}^{-1}$.

Table 2. Multivariable logistic regression models for the treatment of smoking, hypertension and hypercholesterolaemia

\begin{tabular}{|c|c|c|c|c|}
\hline & $\mathrm{N}$ & Treated (\%) & OR $(95 \% \mathrm{Cl})$ & P-value \\
\hline \multicolumn{5}{|l|}{ Smoking a } \\
\hline Underweight & 885 & $95(11)$ & $0.74(0.58,0.95)$ & 0.017 \\
\hline Normal weight & 11722 & 1648 (14) & 1.00 & - \\
\hline Overweight & 11769 & $1830(16)$ & $1.08(0.99,1.18)$ & 0.070 \\
\hline Obese & 5897 & 993 (17) & $1.16(1.05,1.29)$ & 0.005 \\
\hline Severe obesity & 2090 & $374(18)$ & $1.20(1.04,1.39)$ & 0.016 \\
\hline Morbid obesity & 1147 & $227(20)$ & $1.32(1.11,1.58)$ & 0.002 \\
\hline Missing BMI & 21726 & $1571(7)$ & $0.51(0.35,0.93)$ & $<0.001$ \\
\hline \multicolumn{5}{|l|}{ Hypertension $^{\mathrm{a}, \mathrm{b}}$} \\
\hline Underweight & 1148 & $781(68)$ & $0.72(0.62,0.84)$ & $<0.001$ \\
\hline Normal weight & 20394 & $13787(68)$ & 1.00 & - \\
\hline Overweight & 32087 & $22343(70)$ & $1.21(1.16,1.27)$ & $<0.001$ \\
\hline Obese & 19064 & $13744(72)$ & $1.50(1.41,1.58)$ & $<0.001$ \\
\hline Severe obesity & 7757 & 5707 (74) & $1.75(1.62,1.88)$ & $<0.001$ \\
\hline Morbid obesity & 4319 & 3107 (72) & $1.75(1.59,1.92)$ & $<0.001$ \\
\hline Missing BMI & 36000 & $13322(37)$ & $0.45(0.41,0.50)$ & $<0.001$ \\
\hline \multicolumn{5}{|c|}{ Hypercholesterolaemia ${ }^{\mathrm{a}, \mathrm{b}}$} \\
\hline Underweight & 706 & $424(60)$ & $0.70(0.58,0.84)$ & $<0.001$ \\
\hline Normal weight & 14158 & $9291(66)$ & 1.00 & - \\
\hline Overweight & 22809 & $16574(73)$ & $1.35(1.28,1.43)$ & $<0.001$ \\
\hline Obese & 13180 & 9957 (76) & $1.59(1.48,1.72)$ & $<0.001$ \\
\hline Severe obesity & 4998 & 3852 (77) & $1.83(1.66,2.02)$ & $<0.001$ \\
\hline Morbid obesity & 2591 & 1981 (76) & $1.83(1.61,2.07)$ & $<0.001$ \\
\hline Missing BMI & 16361 & $7426(45)$ & $0.70(0.64,0.78)$ & $<0.001$ \\
\hline
\end{tabular}

Abbreviations: BMl, body mass index; $\mathrm{Cl}$, confidence interval; $\mathrm{N}$, represents the number of patients with the risk factor; OR, odds ratio. ${ }^{\mathrm{a}} \mathrm{Adjusted}$ for age, gender, CHD, stroke, type 2 diabetes and socioeconomic status. ${ }^{b}$ Adjusted for smoking status.

controlled (Table 3). Control of hypertension and hypercholesterolaemia was lower in those with missing BMI (AOR 0.65, 0.60-0.72, $P<0.001)$. A diagnosis of $C H D$, stroke and diabetes was associated with greater odds of controlled hypertension and hypercholesterolaemia, whilst socioeconomic deprivation was associated with worse cholesterol, but not hypertension, control. Additional analyses were performed, excluding patients with existing diabetes CHD or stroke. These analyses showed that the associations of hypertension control with BMl category were similar in a primary prevention cohort but cholesterol control was no longer associated with BMI category.

\section{DISCUSSION}

Summary of key findings

Obesity is associated with more frequent hypertension and hypercholesteroalemia; higher rates of treatment for smoking, 
Table 3. Multivariable logistic regression models for the control of hypertension and hypercholesterolaemia in treated patients

\begin{tabular}{|c|c|c|c|c|c|c|c|c|}
\hline & \multirow[b]{2}{*}{$\mathrm{N}$} & \multicolumn{3}{|c|}{ Hypertension } & \multirow[b]{2}{*}{$\mathrm{N}$} & \multicolumn{3}{|c|}{ Hypercholesterolaemia } \\
\hline & & Controlled (\%) & OR $(95 \% C I)^{\mathrm{a}, \mathrm{b}}$ & P-value & & Controlled (\%) & OR $(95 \% C l)^{\mathrm{a}}$ & P-value \\
\hline \multicolumn{9}{|l|}{ BMI category } \\
\hline Underweight & 781 & $501(64)$ & $0.84(0.71-0.98)$ & 0.031 & 424 & $202(48)$ & $0.63(0.51-0.78)$ & $<0.001$ \\
\hline Normal weight & 13787 & 9505 (69) & 1.00 & - & 9291 & $5637(61)$ & 1.00 & - \\
\hline Overweight & 22343 & $15341(69)$ & $0.93(0.88-0.98)$ & 0.004 & 16574 & $10645(64)$ & $1.10(1.04-1.16)$ & $<0.001$ \\
\hline Obese & 13744 & $9251(67)$ & $0.84(0.79-0.89)$ & $<0.001$ & 9957 & $6487(65)$ & $1.09(1.03-1.16)$ & 0.004 \\
\hline Severe obesity & 5707 & 3759 (66) & $0.78(0.73-0.84)$ & $<0.001$ & 3852 & $2520(65)$ & 1.08 (1.00 1.18) & 0.059 \\
\hline Morbid obesity & 3107 & 1912 (62) & $0.63(0.590 .69)$ & $<0.001$ & 1981 & $1343(68)$ & 1.19 (1.06 1.34) & 0.005 \\
\hline Missing BMI & 13322 & $6746(51)$ & $0.54\left(\begin{array}{lll}0.51 & 0.58)\end{array}\right.$ & $<0.001$ & 7426 & $3073(41)$ & 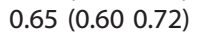 & $<0.001$ \\
\hline
\end{tabular}

Abbreviations: $\mathrm{BMI}$, body mass index; $\mathrm{Cl}$, confidence interval; $\mathrm{N}$, number receiving treatment; $\mathrm{OR}$, odds ratio. ${ }^{\mathrm{a}}$ Controlling for age, gender, co-morbidities, smoking status and socioeconomic status. ${ }^{\mathrm{b}}$ Also controlling for number of antihypertensive drug classes.

hypertension and hypercholesterolaemia, but worse control of hypertension. Separate estimates were presented for severe and morbid obesity, showing that associations were graded according to level of obesity. Control of hypertension was negatively associated with BMI category, with morbidly obese patients less likely to have controlled BP than those who were of normal weight. Evaluation of the number of classes of antihypertensive drugs prescribed showed that maximal antihypertensive therapy was not utilised in a high proportion of patients. Further research is needed to evaluate the use of different classes of drugs, and different agents within classes, in order to identify optimal hypertensive therapy for obese patients. Conversely, obesity was associated with better control of total cholesterol. The absolute magnitude of effects was modest but these small differences may be of public health importance when a frequent condition is managed in a large population.

\section{Comparison with the literature}

Obesity is known to be associated with greater cardiovascular risk $^{16}$ and a higher incidence of cardiovascular events. ${ }^{17}$ Hypertension is associated with increased morbidity and mortality from major cardiovascular diseases. ${ }^{18}$ The incidence ${ }^{17}$ and prevalence ${ }^{19}$ of hypertension are greater as BMI category increases. In the Framingham cohort, ${ }^{20}$ obese individuals were more likely to receive treatment for hypertension but there were no differences in hypertension control. Less consistent associations have been reported for treatment and control of hypercholesterolaemia. In the Framingham study, hypercholesterolaemia, based on a cutpoint of $6.2 \mathrm{mmoll}^{-1}$, was not as strongly associated with obesity as was hypertension, ${ }^{17}$ but rates of lipid-lowering therapy were higher in the obese participants. ${ }^{20}$ However, several factors potentially confound this relationship. Access and adherence to lipid-lowering therapy may sometimes depend on the socioeconomic deprivation category. ${ }^{21}$

\section{Strengths and limitations}

The study had the strength of a very-large sample, drawn from a nationally representative population of eligible participants. The size of the sample enabled us to obtain precise estimates for participants with severe and morbid obesity. However, we acknowledge that analysis of clinical records for key measures suffered from several limitations. Nearly $40 \%$ of participants did not have recent BMI values recorded, consistent with the infrequent monitoring of BMI in primary care. ${ }^{11}$ The distribution of BMI category was generally similar to those observed in national survey data ${ }^{22}$ but confounding by indication may arise if $\mathrm{BMI}$ is more likely to be measured in patients who are ill or have elevated risk factor values. Obese patients may be more likely to have their BP and lipid levels documented compared with their normal weight peers. ${ }^{23}$ Recording of measurements may be associated with treatment. Errors in BP measurement may be greater in more obese people, if a correctly fitting BP cuff is not used. The use of different drug classes may vary by obesity category requiring further in-depth analysis. We reported on total cholesterol values because lipoprotein fractions are less frequently recorded into electronic health records. However, use of LDL:HDL ratios might lead to different interpretations if $\mathrm{HDL}$ levels are lower in obesity. We used a cut-point of $5 \mathrm{mmolI}^{-1}$ to define hypercholesterolaemia and control, but lower treatment targets are sometimes recommended. We were not able to analyse data for some relevant confounders including physical activity, alcohol consumption, educational level, ethnicity, family history or duration of hypertension. We conducted sensitivity analyses to evaluate the relevance of cardiovascular comorbidity for the measures evaluated, but we acknowledge that there may be other relevant co-morbidities, such as type 1 diabetes, which might be present and lower frequency.

\section{Implications for future research and practice}

The results of this large population-based study reveal that treatment and control of cardiovascular risk remain sub-optimal in both obese and non-obese patients. However, the status of three major modifiable risk factors for cardiovascular disease differs according to weight status. Smoking is generally less frequent as BMI increases but obese smokers are more likely to receive smoking cessation therapy. Obese individuals more frequently have hypercholesterolaemia, are more likely to receive treatment, and tend to be slightly better controlled. However, while hypertension is more frequent in obesity, and there is evidence of a greater intensity of antihypertensive treatment as BMl category increases, rates of hypertension control remain less satisfactory. These associations were broadly consistent in men and women but further research is required to explore possible gender differences in the impact of obesity. The results identify the increase in obesity as a major obstacle to improved hypertension management, perhaps now threatening the continued decline in cardiovascular disease. While weight reduction may be associated with improved BP and reduced cardiovascular risk $^{16}$ non-surgical weight-loss interventions presently have generally limited long-term effects. ${ }^{24,25}$ Although the pathophysiological mechanisms of hypertension in obesity have been well studied, ${ }^{2}$ the reasons why hypertension is more difficult to control in obese subjects deserve more research. Improved intervention strategies, and optimal therapeutic interventions, for hypertension in obesity may then be developed. 
What is known about topic

- Obesity is increasing worldwide with especially rapid increases in severe and morbid obesity.

- Preventive medical interventions to reduce obesity-associated cardiovascular risk are important but few previous studies have distinguished different levels of obesity severity.

What this study adds

- We analysed primary care electronic health record data for 153308 participants including 46149 who were obese, including 11059 with severe obesity and 5833 with morbid obesity.

- We found that treatment of smoking and hypercholesterolaemia increased with increasing body mass index category.

- Age-standardised hypertension prevalence was twice as high in morbid obesity compared with normal weight. Although treatment rates increased with BMI category, control of hypertension was less likely to be achieved.

- Improved management of obesity and obesity-associated hypertension should be important objectives for preventive medical care.

\section{CONFLICT OF INTEREST}

The authors declare no conflict of interest.

\section{ACKNOWLEDGEMENTS}

This study is based in part on data from the Clinical Practice Research Datalink (CPRD) obtained under license from the UK Medicines and Healthcare products Regulatory Agency (UKMHRA). This research was supported by the National Institute for Health Research (NIHR) Biomedical Research Centre at Guy's and St Thomas' NHS Foundation Trust and King's College London, and by the UK National Prevention Research Initiative (UKNPRI).

\section{REFERENCES}

1 Fox CS, Pencina MJ, Wilson PWF, Paynter NP, Vasan RS, D'Agostino RB. Lifetime risk of cardiovascular disease among individuals with and without diabetes stratified by obesity status in the Framingham Heart Study. Diabetes Care 2008; 31: 1582-1584.

2 Landsberg L, Aronne LJ, Beilin LJ, Burke V, Igel LI, Lloyd-Jones D et al. Obesityrelated hypertension: pathogenesis, cardiovascular risk, and treatment: a position paper of The Obesity Society and the American Society of Hypertension. J Clin Hypertens (Greenwich) 2013; 15: 14-33.

3 Abdullah A, Amin FA, Stoelwinder J, Tanamas SK, Wolfe R, Barendregt J et al. Estimating the risk of cardiovascular disease using an obese-years metric. BMJ Open 2014; 4: e005629.

4 Merlotti C, Morabito A, Pontiroli AE. Prevention of type 2 diabetes; a systematic review and meta-analysis of different intervention strategies. Diabetes Obes Metab 2014; 16: 719-727.

5 Murray CJL, Richards MA, Newton JN, Fenton KA, Anderson HR, Atkinson C et al. UK health performance: findings of the Global Burden of Disease Study 2010. The Lancet 2013; 381: 997-1020.

6 Falaschetti $\mathrm{E}$, Mindell J, Knott C, Poulter N. Hypertension management in England: a serial cross-sectional study from 1994 to 2011. Lancet 2014; 383: 1912-1919.

7 Chopra I, Kamal KM, Candrilli SD. Variations in blood pressure and lipid goal attainment in primary care. Curr Med Res Opin 2013; 29: 1115-1125.

8 Bramlage P, Pittrow D, Wittchen HU, Kirch W, Boehler S, Lehnert $\mathrm{H}$ et al. Hypertension in overweight and obese primary care patients is highly prevalent and poorly controlled. Am J Hypertension 2004; 17: 904-910.
9 Banegas JR, López-García E, Dallongeville J, Guallar E, Halcox JP, Borghi C et al. Achievement of treatment goals for primary prevention of cardiovascular disease in clinical practice across Europe: the EURIKA study. Eur Heart $J$ 2011; 32: 2143-2152.

10 Williams T, van Staa T, Puri S, Eaton S. Recent advances in the utility and use of the General Practice Research Database as an example of a UK Primary Care Data resource. Ther Adv Drug Safety 2012; 3: 89-99.

11 Booth HP, Prevost AT, Gulliford MC. Epidemiology of clinical body mass index recording in an obese population in primary care: a cohort study. $J$ Public Health 2013; 35: 67-74.

12 Booth HP, Prevost AT, Gulliford MC. Validity of smoking prevalence estimates from primary care electronic health records compared with national population survey data for England, 2007 to 2011. Pharmacoepidemiol Drug Safety 2013; 22: 1357-1361.

13 Sever P. New Hypertension Guidelines from the National Institute for Health and Clinical Excellence and the British Hypertension Society. J Renin-AngiotensinAldosterone Syst 2006; 7: 61-63.

14 Communities and Local Government The English Indices of Deprivation 2010. London: Department for Communities and Local Government, 2011. https:// www.gov.uk/government/uploads/system/uploads/attachment_data/file/6320/ 1870718.pdf accessed 12th March 2015.

15 Eurostat task force. Revision of the European Standard Population: Report of Eurostat's Taskforce. European Commission: Luxembourg, 2013.

16 Wannamethee SG, Shaper AG, Walker M. Overweight and obesity and weight change in middle aged men: impact on cardiovascular disease and diabetes. J Epidemiol Community Health 2005; 59: 134-139.

17 Wilson PF, D'Agostino RB, Sullivan L, Parise H, Kannel WB. Overweight and obesity as determinants of cardiovascular risk: the Framingham experience. Arch Intern Med 2002; 162: 1867-1872.

18 Rapsomaniki E, Timmis A, George J, Pujades-Rodriguez M, Shah AD, Denaxas S et al. Blood pressure and incidence of twelve cardiovascular diseases: lifetime risks, healthy life-years lost, and age-specific associations in 1.25 million people. Lancet 2014; 383: 1899-1911.

19 Stamler R, Stamler J, Riedlinger WF, Algera G, Roberts RH. Family (parental) history and prevalence of hypertension: results of a nationwide screening program. JAMA 1979; 241: 43-46.

20 Molenaar EA, Hwang S-J, Vasan RS, Grobbee DE, Meigs JB, D'Agostino RB et al. Burden and rates of treatment and control of cardiovascular disease risk factors in obesity: The Framingham Heart Study. Diabetes Care 2008; 31: 1367-1372.

21 Fleetcroft R, Schofield P, Ashworth M. Variations in statin prescribing for primary cardiovascular disease prevention: cross-sectional analysis. BMC Health Serv Res 2014; 14: 414.

22 Joint Health Surveys Unit. Health Survey for England - 2011 Trend Tables. Health and Social Care Information Centre: Leeds, 2014.

23 Rose SA, Turchin A, Grant RW, Meigs JB. Documentation of body mass index and control of associated risk factors in a large primary care network. BMC Health Serv Res 2009; 9: 13.

24 Loveman E, Frampton GK, Shepherd J, Picot J, Cooper K, Bryant J et al. The clinical effectiveness and cost-effectiveness of long-term weight management schemes for adults: a systematic review. Health Technol Assess 2011; 15: 1-182.

25 Booth HP, Prevost AT, Wright AJ, Gulliford MC. Effectiveness of behavioral weight loss interventions delivered in a primary care setting: a systematic review and meta-analysis. Fam Pract 2014; 31: 643-653.

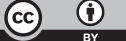

This work is licensed under a Creative Commons Attribution 4.0 International License. The images or other third party material in this article are included in the article's Creative Commons license, unless indicated otherwise in the credit line; if the material is not included under the Creative Commons license, users will need to obtain permission from the license holder to reproduce the material. To view a copy of this license, visit http://creativecommons.org/licenses/ by/4.0/ 